\title{
Patients' satisfaction and prevalence of complications on surgical extraction of third molar
}

This article was published in the following Dove Press journal:

Patient Preference and Adherence

10 February 2015

Number of times this article has been viewed

\author{
Crystal TY Lee \\ Shinan Zhang \\ Yiu Yan Leung \\ Samantha KY Li \\ Cissy C Tsang \\ Chun-Hung Chu \\ Faculty of Dentistry, The University \\ of Hong Kong, Hong Kong SAR, \\ People's Republic of China
}

Correspondence: $\mathrm{CH}$ Chu

IB30, Prince Philip Dental Hospital,

34 Hospital Road, Hong Kong SAR,

People's Republic of China

Tel +852 28590287

Fax +85228582532

Email chchu@.hku.hk
Objectives: To study patients' satisfaction and prevalence of complications in surgical extraction of impacted third molar by senior dentists and recently graduated dentists in a university dental clinic.

Method: Patients who had impacted third molar extraction in a university dental clinic by two associate dentists who had $<2$ years of experience and two senior dentists who had $>15$ years of experience were evaluated in this study. Patients' age, sex, history of pericoronitis, tooth extracted, and radiographic assessment of the impacted tooth were recorded. Immediately after suture removal, the patients were invited to indicate their satisfaction on a Likert scale of $1-5$.

Results: A total of 546 patients received extraction, and 251 patients were operated by associate dentists. Patient satisfaction was higher among those who had noncomplicated surgery $(P=0.007)$, short treatment time $(P<0.001)$, and had no postsurgical emergency appointments $(P<0.001)$. The prevalence of seeking postsurgical emergency appointments was $9.2 \%$. The reasons were severe pain (4.8\%), swelling (2.6\%), bleeding (2.4\%), alveolar osteitis $(0.9 \%)$, paresthesia $(0.9)$, and trismus $(0.5 \%)$. The prevalence of postsurgical complication(s) in associate dentists and senior dentists was $11.6 \%$ and $7.1 \%$, respectively $(P=0.050)$. The mean satisfaction scores for associate dentists and senior dentists were 4.17 and 3.95 , respectively $(P=0.002)$.

Conclusion: Although a higher rate of postsurgical complications was observed among the patients treated by the recently graduated dentists, their patients' satisfaction scores were higher than that of the senior dentists. Around $9 \%$ of patients attended postsurgical emergency appointments, and their common reason was severe pain.

Keywords: dental satisfaction, dentistry, complications, extraction, third molar

\section{Introduction}

Third molar surgery is one of the most common surgical procedures performed in general dentistry. A recent study reported that an annual cost of over US\$3 billion was used for extracting third molars in the United States, and more than $£ 5$ million was spent for extractions in England and Wales. ${ }^{1}$ Not all patients with impacted third molars developed symptoms. Although the surgery in some cases may be carried out simply by using forceps and/or elevators, many cases require surgical procedures that involve the raising of a flap and the removal of alveolar bone. Therefore, the risks of surgical complications must be weighed against the benefits of the extraction. Mercier and Precious performed a critical review of the literature and found there were no long-term studies that validate the benefit of early or of on-purpose delayed extraction of asymptomatic third molars. ${ }^{2}$ Therefore, they concluded that absolute indications and contraindications for the extraction of third molars could not be established. The prudent 
course of action for dentists to follow should be based on rational clinical decision-making using traditional methods of evaluation, so as to effect the optimal outcome, keeping the interests of the individual patient above all else. ${ }^{2}$

The benefits of third molar surgery include the relief of pain, the prevention of caries and periodontal disease, the facilitation of orthodontic treatment and orthognathic surgery, and the prevention of pathological conditions such as dentigerous cyst formation and external root resorption of the adjacent second molar. Like most surgical procedures, third molar surgery bears its own risks of intraoperative and postoperative complications. Pain, swelling, and trismus are among the most common complications after third molar removal. Of more concern is the risk of nerve damage, particularly the inferior alveolar nerve and the lingual nerve damage after mandibular third molar surgery, leading to paresthesia of the chin, lower lip, and/or the tongue.

A prospective clinical study in Hong Kong has shown an incidence of $0.35 \%$ for permanent inferior alveolar nerve deficit and $0.69 \%$ for permanent lingual nerve deficit after mandibular third molar surgeries. ${ }^{3}$ A review article by Bouloux et al in 2007 also listed alveolar osteitis, with a frequency of $0.3 \%-26 \%$; bleeding, with a frequency of $0.2 \%-5.8 \%$; and damage to adjacent teeth, with an incidence of $0.3 \%-0.4 \%$, to be possible complications. ${ }^{4}$ Other less commonly reported complications include displacement of the third molar, mandibular fracture, tooth aspiration, and oro-antral communication.

In the evaluation of the quality of clinical care, the incidence of complication is merely one factor that is taken into consideration. More importantly, an evaluation of patients' satisfaction on the quality of treatment and care may be more appropriate. Patients' satisfaction is a key to patient compliance and the business success of the dental clinic. Measures of patient satisfaction with dental care may provide useful information to those who want to understand or to predict patient behavior and to those who want to evaluate the dental care providers and services. ${ }^{5}$ A literature review summarized factors affecting patient satisfaction in general dental care into a generic list of five subjective and objective items: technical competence, interpersonal factors, convenience, costs, and facilities. ${ }^{6}$ Common surveys that are used to clinically assess patients' satisfaction include the Dental Satisfaction Questionnaire and the Dental Visit Satisfaction Scale.

The on-campus University Health Service (UHS) dental clinic is established to provide comprehensive dental service to the full-time and part-time students and staff of the University of Hong Kong, and their dependants. ${ }^{7}$ Apart from senior dentists, there are recently graduated associated dentists to serve patients. The purpose of this study was to study the prevalence of complications and patients' satisfaction on surgical extraction of third molar in a university dental clinic by senior dentists and associate dentists.

\section{Methods}

This study was performed from September 2006 to June 2007 in the UHS dental clinic. Students who attended the dental clinic and required surgical extraction of their impacted third molars were scheduled for extraction. The allocation of patient to the operating dentist was based primarily on the availability of surgical treatment session that was assigned to UHS dentists. Two of the UHS dentists were associate dentists who had $<2$ years of experience, and two were senior dentists who had $>15$ years of experience and advanced training in general dental practice. Patients who received surgical extraction by these four UHS dentists were evaluated in this study.

Patients' age, sex, history of pericoronitis, and tooth extracted were recorded. Radiographic assessment of the impacted tooth was performed using Winter's classification, which classifies the impaction into horizontal, mesioangular, vertical, distoangular, buccoangular, linguoangular, and inverted impaction. The depth of impaction was measured according to the Winter's lines. The root anatomy was categorized as single-rooted or multi-rooted. Superimposition of the tooth onto the inferior dental canal was noted.

In this study, the level of difficulty of the surgery was assessed by an independent dentist as follows: the impacted third molar was first classified using Pell and Gregory method. ${ }^{8}$ Pell and Gregory Class A, B, and $\mathrm{C}$ were given a score of 1, 2, and 3, respectively; Pell and Gregory Class 1, 2 , and 3 were given a score of 1,2 , and 3 respectively. If the sum of the two scores was $<4$, the surgery was classified as "simple". The surgery was considered "moderate" if the sum was 4 , and "difficult" if the sum was $>4$.

Removal of suture would normally be performed 1 week after the surgical extraction. After the removal of suture and before leaving the reception counter, the patients were invited to indicate their general satisfaction on a Likert scale of 1-5. They were also asked about their impression of the surgical treatment time as being fast, reasonable, or prolonged.

\section{Sample size determination}

In this study, the primary outcomes were the prevalence of complications and patients' satisfaction. Sample size determination was based on these two primary outcomes by 
senior dentists and recently graduated dentists with the use of $\mathrm{G}^{*}$ Power software (version 3.1.6; Franz Faul, Universität Kiel, Kiel, Germany). By assuming the proportions as $10 \%$ and $2.5 \%$ in prevalence of complications and allocation ratio as $1: 1$, a total of at least 256 patients were needed to have an $80 \%$ chance (power) $(\beta=0.20)$ at a 0.05 significance level in a one-tailed test. Besides, assuming the standard deviation of the satisfaction scores as 0.5 and allocation ratio as $1: 1$, a total of at least 200 patients were needed to have an $80 \%$ chance (power) $(\beta=0.20)$ to detect the mean difference of satisfaction scores as 0.2 between senior dentists and recently graduated dentists at a 0.05 significance level in a two-tailed test. Considering the possible nonresponse rate as $35 \%,{ }^{7}$ at least 394 patients would be recruited.

\section{Statistical analysis}

The data were analyzed using the computer software SPSS Statistics - V20.0 (IBM Corporation, Armonk, NY, USA). Student's $t$-test was used to study the differences in patients' age, depth of the impacted third molar, and patient satisfaction between the two dentist groups. Chi-square test was used to determine the difference in distribution of sex, lower tooth location, history of pericoronitis, Winter's classification of impaction, superposition of inferior dental canal, root anatomy, surgical assessment, impression of treatment time, and postsurgical complication between the two dentist groups. Also, to investigate the effects of different factors on patient satisfaction, separated one-way analysis of variance or bivariate linear regression models were performed initially. Because of apparent statistical interaction, an additional two-way analysis of variance of the Winter's classification of impaction and surgical assessment on patient satisfaction were also applied. Then multiway analysis of covariance or analysis of variance with those significant indicators altogether was performed keeping the main effects of the interaction effect significant. To interpret the effects, pairwise comparisons would be performed with Bonferroni adjustment. All the statistical tests, except the test on postoperative complications by dentist group, were two-tailed, and the significance level was set at 0.05 .

\section{Results}

A total of 546 patients received surgical extraction by the two associate dentists and two senior dentists (Table 1). Their mean (standard deviation) age was 22.4 (2.5). There were 340 (62.3\%) female patients; 92 (16.8\%) patients had a history of pericoronitis, and $251(46.0 \%)$ patients were operated by associate dentists. In $281(51.5 \%)$ patients, the impacted molar was on the left side. Radiograph revealed $268(49.1 \%)$ teeth to be superimposed onto the inferior canal and $140(25.6 \%)$ teeth with single or fused root. The impacted molars were classified as horizontal impaction (39.6\%), mesioangular impaction (37.0\%), vertical impaction $(18.9 \%)$, or distoangular impaction (4.6\%). The mean (standard deviation) depth of impaction was 4.9 (3.7) $\mathrm{mm}$. Surgical assessment showed that there were more simple extractions and less difficult extractions performed by the associated dentists $(P=0.028)$.

The prevalence of postsurgical complication was $9.2 \%$ (Figure 1). The complications were severe postoperative pain (4.8\%), swelling $(2.6 \%)$, bleeding $(2.4 \%)$, alveolar osteitis $(0.9 \%)$, paresthesia $(0.9)$, and trismus $(0.5 \%)$. Compared with those patients treated by the associate dentists, more patients rated their extraction as fast and fewer patients rated their extraction as prolonged by the senior dentists. However, the difference was not significant $(P=0.065)$. The prevalence of postsurgical complication in associate dentists and senior dentists was $11.6 \%$ and $7.1 \%$, respectively $(P=0.050$, onetailed test). The mean (standard deviation) satisfaction scores for associate dentists and senior dentists were 4.17 (0.64) and 3.95 (0.72), respectively ( $P=0.002)$.

Before investigating the factors related to the patient satisfaction, due to rare cases in some categories, those cases with distoangular in Winter's classification were excluded from the model and the surgical assessment was recorded as a binary variable, which was divided by noncomplicated (simple) cases and complicated (combing moderate and difficult) cases. Univariate analyses showed that the patient satisfaction score was related to the surgical assessment $(P=0.046)$, dentist $(P=0.002)$, impression of treatment time $(P<0.001)$, and postsurgical complication $(P<0.001)$. The two-way model showed that the patient satisfaction score was related to the interaction effect of Winter's classification of impaction and surgical assessment $(P=0.040)$. The final model of the multiway model with those significant indicators altogether showed that the patient satisfaction score was related to the dentist, postsurgical complications, impression of treatment time, and the interaction effect of surgical assessment and Winter's classification of impaction $\left(R^{2}=0.210\right.$, adjusted $R^{2}=0.189$ ) (Table 2). The Levene test with a $P$-value of 0.223 indicated that there was no evidence that the assumption of equal standard deviations was violated. Also, lack-of-fit test confirmed that the relationship between the dependent variables and the independent variables could be adequately described by the model $(P=0.480)$. 
Table I Variables studied according to operator experience $(\mathrm{N}=546)$

\begin{tabular}{|c|c|c|c|c|}
\hline & \multirow[t]{2}{*}{ All (N) } & \multicolumn{2}{|l|}{ Operator experience } & \multirow[t]{2}{*}{$P$-value } \\
\hline & & Senior dentists $(\mathbf{N})$ & Associate dentists (N) & \\
\hline Sex & & & & 0.479 \\
\hline Male & $37.7 \%(206)$ & $36.3 \%(107)$ & $39.4 \%(99)$ & \\
\hline Female & $62.3 \%(340)$ & $63.7 \%(188)$ & $60.6 \%(152)$ & \\
\hline Age (mean $\pm S D)$ & $22.4 \pm 2.5(546)$ & $22.5 \pm 2.9(295)$ & $22.1 \pm 1.9(25 I)$ & 0.110 \\
\hline History of pericoronitis & & & & 0.731 \\
\hline Yes & $16.8 \%(92)$ & $16.3 \%(48)$ & $17.5 \%(44)$ & \\
\hline No & $83.2 \%(454)$ & $83.7 \%(147)$ & $82.5 \%(207)$ & \\
\hline Lower molar location & & & & 1.000 \\
\hline Left & $5 \mathrm{I} .5 \%(28 \mathrm{I})$ & $51.5 \%(152)$ & $51.4 \%(129)$ & \\
\hline Right & $58.5 \%(265)$ & $48.5 \%(143)$ & $48.6 \%(122)$ & \\
\hline Winter's classification & & & & 0.529 \\
\hline Horizontal & $39.6 \%(216)$ & $37.3 \%(110)$ & $42.2 \%(106)$ & \\
\hline Mesioangular & $37.0 \%(202)$ & $39.7 \%(117)$ & $33.9 \%(85)$ & \\
\hline Vertical & $18.9 \%(103)$ & $18.3 \%(54)$ & $19.5 \%(49)$ & \\
\hline Distoangular & $4.6 \%(25)$ & $4.7 \%(14)$ & $4.4 \%(\mathrm{II})$ & \\
\hline Depth of impaction/mm (mean \pm SD) & $4.9 \pm 3.7(546)$ & $5.2 \pm 3.8(295)$ & $4.6 \pm 3.6(251)$ & 0.049 \\
\hline Superimposition of ID canal & & & & 0.230 \\
\hline Yes & $49.1 \%(268)$ & $51.5 \%(152)$ & $46.2 \%(116)$ & \\
\hline No & $50.9 \%(278)$ & $48.5 \%(143)$ & $53.8 \%(135)$ & \\
\hline Root anatomy & & & & 0.116 \\
\hline Single/fused root & $25.6 \%(140)$ & $28.5 \%(84)$ & $22.3 \%(56)$ & \\
\hline Multiroot & $74.4 \%(406)$ & $71.5 \%(211)$ & $77.7 \%(195)$ & \\
\hline Surgical assessment & & & & 0.028 \\
\hline Simple & $40.3 \%(220)$ & $37.3 \%(110)$ & $43.8 \%(110)$ & \\
\hline Moderate & $56.6 \%(309)$ & $58.0 \%(|7|)$ & $55.0 \%(138)$ & \\
\hline Difficult & $3.1 \%(17)$ & $4.7 \%(14)$ & $1.2 \%(3)$ & \\
\hline Impression of treatment time & & & & 0.065 \\
\hline Fast & $29.7 \%(105)$ & $34.9 \%(52)$ & $26.0 \%(53)$ & \\
\hline Reasonable & $64.3 \%(227)$ & $61.7 \%(92)$ & $66.2 \%(135)$ & \\
\hline Prolonged & $5.9 \%(21)$ & $3.4 \%(5)$ & $7.8 \%(16)$ & \\
\hline Postoperative complications & & & & $0.050^{*}$ \\
\hline Yes & $9.2 \%(35)$ & $7.1 \%(21)$ & $11.6 \%(29)$ & \\
\hline No & $90.8 \%(511)$ & $92.9 \%(274)$ & $88.4 \%(222)$ & \\
\hline Patient satisfaction (mean $\pm S D$ ) & $4.08 \pm 0.68(353)$ & $3.95 \pm 0.72(204)$ & $4.17 \pm 0.64(149)$ & 0.002 \\
\hline
\end{tabular}

Note: *One-tailed test.

Abbreviations: ID, inferior dental; SD, standard deviation.

The model showed that patients had higher satisfaction scores if associate dentists rather than senior dentists did the surgical extraction $(P<0.001)$. Patients without postsurgical complications also had higher satisfaction score $(P<0.001)$. Pairwise comparisons showed that patients who had the impression of fast surgery had significantly higher patient satisfaction scores than those who had the impression of reasonable time $(P<0.001)$ or prolonged surgery $(P=0.001)$ with adjustment for other covariates. There existed an interaction effect of surgical assessment and Winter's classification of impaction on the satisfaction scores $(P=0.007)$. In mesioangular classification, noncomplicated cases had significantly higher patient satisfaction scores than complicated cases $(P=0.001)$ with adjustment for other covariates. But in other Winter's classifications, there was no significant difference in patient satisfaction scores between complicated and noncomplicated cases.

\section{Discussion}

This study is generated by the audit of the clinical service of the UHS, and thus, no ethic approval was sought from the Institutional Review Board. Patients' satisfaction is one of the main items used to assess the clinical service because it is one of the key elements used in assessing quality of care. ${ }^{9}$ Moreover, patients' satisfaction with dental treatment is important because it will affect their service utilization 


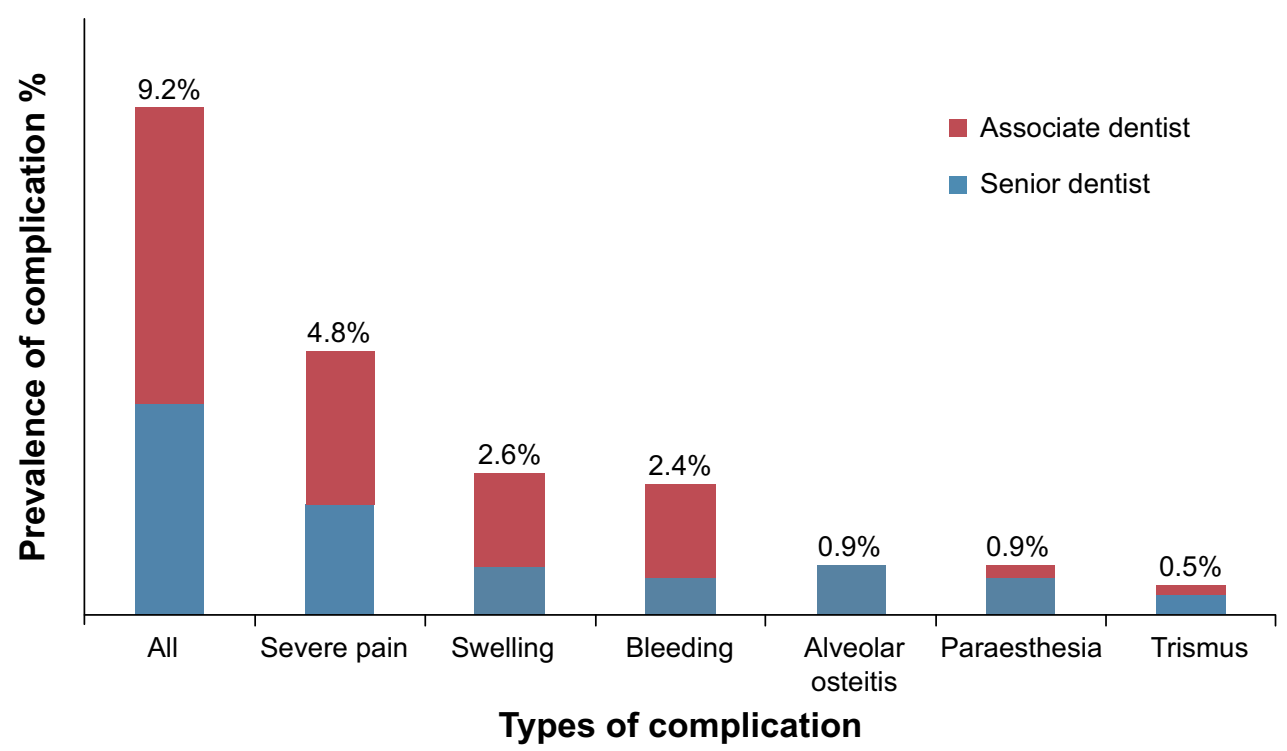

Figure I Prevalence of postsurgical complications of third molar extraction.

pattern. Satisfied patients often have good compliance, fewer broken appointments, and less pain and anxiety. The UHS conducted regular patients' satisfaction survey to evaluate the quality of the service and to make changes for improvement of the service.

Dental Satisfaction Questionnaire is a 19-item selfadministered questionnaire developed by Davies and Ware. ${ }^{10}$ They proposed separate scoring of five scales, which were access, availability or convenience, cost, pain, and quality. These five scales represent main sources of satisfaction and dissatisfaction with dental care providers and services. In addition, an overall dental satisfaction index was also constructed. In this study, the overall dental satisfaction index was evaluated in the third molar surgery. This survey had a nonresponse rate of around one-third (35.3\%), which is considered acceptable for anonymous survey. ${ }^{5}$

Table 2 Variables related to patient satisfaction in final multiway model $(\mathrm{N}=337)$

\begin{tabular}{|c|c|c|c|c|c|}
\hline & \multirow[t]{2}{*}{ Estimate } & \multicolumn{2}{|c|}{ 95\% confidence interval } & \multirow[t]{2}{*}{$P$-value } & \multirow{2}{*}{$\begin{array}{l}\text { Pairwise } \\
\text { comparison }\end{array}$} \\
\hline & & Lower limit & Higher limit & & \\
\hline \multicolumn{6}{|l|}{ Dentist } \\
\hline Associate dentists & 0.27 & 0.14 & 0.40 & $<0.001$ & \\
\hline \multicolumn{6}{|l|}{ Senior dentists* } \\
\hline Impression of treatmen & & & & $<0.001$ & $(1)>(2),(3)$ \\
\hline Fast (I) & 0.59 & 0.28 & 0.89 & & \\
\hline Reasonable (2) & 0.15 & -0.14 & 0.44 & & \\
\hline \multicolumn{6}{|l|}{ Prolonged (3)* } \\
\hline Postoperative complicat & & & & $<0.001$ & \\
\hline No & 0.59 & 0.36 & 0.82 & & \\
\hline \multicolumn{6}{|l|}{ Yes* } \\
\hline Interaction effect of Wi & fication and & essment & & 0.007 & $(3)>(4)$ \\
\hline \multicolumn{6}{|l|}{ Horizontal } \\
\hline Noncomplicated (I) & -0.05 & -0.97 & 0.87 & & \\
\hline Complicated (2) & -0.01 & -0.26 & 0.23 & & \\
\hline \multicolumn{6}{|l|}{ Mesioangular } \\
\hline Noncomplicated (3) & 0.14 & -0.81 & 1.09 & & \\
\hline Complicated (4) & -0.24 & -0.50 & 0.03 & & \\
\hline \multicolumn{6}{|l|}{ Vertical } \\
\hline Noncomplicated (5) & -0.12 & -0.43 & 0.18 & & \\
\hline Complicated $(6)^{*}$ & & & & & \\
\hline
\end{tabular}

Notes: Only significant effects are shown. *Reference group. 
The questionnaires were collected during the following appointment when sutures were removed. A reminder could be sent to all patients to increase the response rate. In addition, the patient satisfaction of those nonresponders was not known. This should be taken into consideration while interpreting the data.

For patients' satisfaction, this study has shown a significantly higher patient satisfaction score for associate dentists compared to senior dentists. This is despite the higher rate of postoperative complications seen in cases performed by associate dentists. Taking into consideration the five main subjective and objective items in the assessment of patient satisfaction - technical competence, interpersonal factors, convenience, costs, and facilities ${ }^{6}$ - three of these items, including convenience, costs, and facilities, were controlled in this study, as all patients received treatment in the same dental clinic. In other words, the only variables for patients' satisfaction were technical competence and interpersonal factors. The higher patient satisfaction score for associate dentists as reflected in this study despite the higher incidence for postoperative complications suggested that technical competence, assumed to be related to incidence for complications, may bear a smaller weighting than interpersonal factors in the subjective assessment of patients' satisfaction. This suggested that interpersonal factors, such as verbal and nonverbal patient communication, are the keys to patient satisfaction. This is in agreement with the findings of many studies. ${ }^{11-13}$ It has been proved that effective verbal and nonverbal communication can aid to reduce patient anxiety and thus improve patient satisfaction. ${ }^{12}$ Effective patient communication can not only allow the patient to have a thorough understanding of the procedure performed and the expected outcomes but also provide comfort during the treatment. All these will help build a positive rapport with the patient. As a novice, it is not surprising to find the associate dentists more willing to spend time and effort in patient communication and building a positive dentist-patient relationship. The increased time spent in patient communication is reflected in the prolonged treatment time as reported by the results of this study.

This study also highlighted the prevalence of the more common complications after third molar surgery, including pain, swelling, bleeding, alveolar osteitis, paresthesia, and trismus. In this study, these complications were noted by the patients and prompted them for emergency treatment. This suggested that pain, swelling, and bleeding were among the complications that caused the most discomfort or worry to the patients, and they feel the need for an urgent, emergency appointment. Knowing this, more emphasis can be placed by physicians during the consent process to psychologically prepare the patient for the known outcomes of third molar surgery such as pain, swelling, and bleeding, so that these complications are of less worry and cause less anxiety to the patient's when they occur. The complication rate reported in this study was shown to be higher for associate dentists than for senior dentists. This was anticipated as associate dentists have less clinical experience, and it has been proved that clinical experience is inversely proportional to the incidence of postoperative complications. ${ }^{14,15}$ The other contributing risk factors for complications may include surgical difficulty, age of the patient, length of operation, and depth of impaction.

Finally, the results of this study have indicated that associate dentists tend to operate on less difficult extractions compared to senior dentists. This is in view of their lack of clinical experience. Despite this disadvantage, patients of associate dentists have shown to have higher satisfaction and a complication rate of only $4.5 \%$ more than the senior dentists. These findings suggest that with proper case selection, dentists with lower levels of clinical experience can still manage third molar extractions, and thus, it is encouraged that these dentists attempt third molar surgeries in selected, less difficult cases. This also allows clinical enrichment of clinical knowledge and skills of the associate dentists who work with senior dentists.

\section{Conclusion}

In this study, patients' satisfaction was higher among those who had noncomplicated surgery, short treatment time, and no postsurgical emergency appointments. Although higher rate of postsurgical complications was observed among the patients of recently graduated dentists, their patients' satisfaction score was higher than that of the senior dentists. Around $9 \%$ of patients attended postsurgical emergency appointments, and the common reason was severe pain. The three most common reasons were postoperative severe pain, swelling, and bleeding.

\section{Acknowledgments}

The authors would like to thank the patients and the UHS of the University of Hong Kong for their support in publishing the manuscript.

\section{Disclosure}

The authors declare that they have no conflicts of interest and/or any financial interests in preparing the manuscript. 


\section{References}

1. Costa MG, Pazzini CA, Pantuzo MC, Jorge ML, Marques LS. Is there justification for prophylactic extraction of third molars? A systematic review. Braz Oral Res. 2013;27:183-188.

2. Mercier P, Precious D. Risks and benefits of removal of impacted third molars. A critical review of the literature. Int J Oral Maxillofac Surg. 1992;21:17-27.

3. Cheung LK, Leung YY, Chow LK, Wong MCM, Chan EKK, Fok YH. Incidence of neurosensory deficits and recovery after lower third molar surgery: a prospective clinical study of 4,338 cases. Int J Oral Maxillofac Surg. 2010;39:320-326.

4. Bouloux GF, Steed MB, Perciaccante VJ. Complications of third molar surgery. Oral Maxillofac Surg Clin North Am. 2007;19:117-128.

5. Chu CH, Lo EC. Patients' satisfaction with dental services provided by a university in Hong Kong. Int Dent J. 1999;49:53-59.

6. Newsome PRH, Wright GH. Patient management: a review of patient satisfaction: dental patient satisfaction: an appraisal of recent literature. Br Dent J. 1999;186:166-170.

7. Chu CH, Yeung CY, Lo EC. Monitoring patient satisfaction with university dental services under two fee-paying systems. Community Dent Oral Epidemiol. 2001;29:390-398.
8. Almendros-Marqués N, Berini-Aytés L, Gay-Escoda C. Evaluation of intraexaminer and interexaminer agreement on classifying lower third molars according to the systems of Pell and Gregory and of Winter. J Oral Maxillofac Surg. 2008;66:893-899.

9. Lo EC, Yeung JC, Chu CH. Fee-paying systems and service patterns in a Hong Kong dental clinic. Int Dent J. 2002;52:261-267.

10. Davies AR, Ware JE Jr. Measuring patient satisfaction with dental care. Soc Sci Med. 1981;15:751-760.

11. Schouten BC, Eijkman MA, Hoogstraten J. Dentists' and patients' communicative behavior and their satisfaction with the dental encounter Community Dent Health. 2003;20:11-15.

12. Corah NL, O'Shea RM, Bissell GD. The dentist-patient relationship: perceptions by patients of dentist behavior in relation to satisfaction and anxiety. J Am Dent Assoc. 1985;111:443-446.

13. Jackson JL, Chamberlin J, Kroenke K. Predictors of patient satisfaction. Soc Sci Med. 2001;52:609-620.

14. Sisk AL, Hammer WB, Shelton DW, Joy ED. Complications following removal of impacted third molars: the role of the experience of the surgeon. J Oral Maxillofac Surg. 1986;44:855-859.

15. Jerjes W, El-Maaytah M, Swinson B, et al. Experience versus complication rate in third molar surgery. Head Face Med. 2006;2:14.
Patient Preference and Adherence

\section{Publish your work in this journal}

Patient Preference and Adherence is an international, peer-reviewed, open access journal that focuses on the growing importance of patient preference and adherence throughout the therapeutic continuum. Patient satisfaction, acceptability, quality of life, compliance, persistence and their role in developing new therapeutic modalities and compounds to optimize

\section{Dovepress}

clinical outcomes for existing disease states are major areas of interest for the journal. This journal has been accepted for indexing on PubMed Central. The manuscript management system is completely online and includes a very quick and fair peer-review system, which is all easy to use. Visit http://www. dovepress.com/testimonials.php to read real quotes from published authors. 